\title{
Accuracy of subjective measurements made with or without previous scores: an important source of error in serial measurement of subjective states
}

\author{
JANE SCOTT AND E. C. HUSKISSON \\ From the Department of Rheumatology, St Bartholomew's Hospital, London ECI
}

SUMMARY Pain severity was assessed on a visual analogue scale in 4 groups of patients receiving $\omega_{0}^{\omega}$ long-term therapy. A comparison was made between pain measurements made with and without access to initial scores. The differences between these measurements increased with the duration of $f_{\infty}$ treatment. Patients tended to overestimate their pain severity when previous scores were not avail-o able. It is suggested that initial scores should be made available when serial measurements of pain $\rightarrow$ are made in long-term experiments.

Most authorities insist that previous measurements should not be made available when a patient is assessed (Hart and Huskisson, 1972). The studies of Jacobsen (1965) are usually quoted in support of this. Our experience has been different. When serial measurements of pain were made in long-term therapeutic studies, patients were often unable to remember their initial state and made assessments which did not necessarily agree with other measures of the progress of their disease. This experiment was designed to assess the accuracy of measurement of pain. A comparison was made between assessments carried out without showing patients their initial score and again after this had been shown to them.

\section{Methods}

Ninety-two patients with painful rheumatic disorders were studied. All were taking part in therapeutic trials involving serial measurement of pain by a visual analogue scale. All patients had an initial assessment before starting treatment. They were then divided into 4 groups according to the duration of their treatment: 2 weeks, 3 to 9 months, 15 to 18 months, and 2 to 3 years. In each group a further assessment was made. First, patients were asked to complete a visual analogue scale without seeing their previous score. They were then shown their initial scores and asked to complete a second assessment of pain.

Accepted for publication 19 December 1978. Correspondence to Dr E. C. Huskisson.
At the end of the experiment the visual analogue scales were divided into 20 parts. The differeness $\overrightarrow{0}$ between assessments made with and without initialco scores has been called the 'error'. If $\mathbf{P}_{0}$ is the inithi score, $P_{1}$ is the pain severity assessed without seeifige the initial score and $P_{2}$ is the pain severity reassessed after the initial score had been made available. Then error is the difference between pain relief derived命 from these 2 measurements or $\left(P_{0}-P_{2}\right)-\left(P_{0}-\right.$ $\left.P_{1}\right)$, the sign, being ignored.

Differences in errors were tested by student's $t^{7}$ test. A correlation coefficient was used to study the degree of agreement between pain scores measured in the 2 ways. The chi-squared test was used to determine the direction of the error.

\section{Results}

The errors in the 4 groups of patients are shown ino Table 1. They rose with increasing duration of treatment, and the difference between the errorso

Table 1 The mean error $\left(P_{0}-P_{2}\right)-\left(P_{0}-P_{1}\right)$ between scores for the 4 groups of patients with standard errors and sample size $(n) . r$ is the correlation coefficient between the pain scores $\left(P_{1}\right.$ and $\left.P_{2}\right)$

\begin{tabular}{|c|c|c|c|c|}
\hline $\begin{array}{l}\text { Duration of } \\
\text { treatment }\end{array}$ & 2 weeks & $\begin{array}{l}3 \text { to } 9 \\
\text { months }\end{array}$ & $\begin{array}{l}15 \text { to } 18 \\
\text { months }\end{array}$ & $\begin{array}{l}2 \text { to } 3 \\
\text { years }\end{array}$ \\
\hline $\begin{array}{l}\text { Mean error } \\
\text { SE } \\
n \\
r\end{array}$ & $\begin{array}{l}1 \cdot 23 \\
0 \cdot 25 \\
22 \\
0.96\end{array}$ & $\begin{array}{l}1 \cdot 67 \\
0 \cdot 38 \\
30 \\
0.92\end{array}$ & $\begin{array}{l}2 \cdot 14 \\
0 \cdot 49 \\
14 \\
0 \cdot 80\end{array}$ & $\begin{array}{l}2 \cdot 77 \\
0 \cdot 76 \\
26 \\
0 \cdot 76\end{array}$ \\
\hline
\end{tabular}


Table 2 Numbers of patients who either overestimated or underestimated their pain severity when initial scores were not available. There were significantly more overestimates after 3 or more months of treatment $\left(\chi^{2}=6.09, P<0.02\right)$

\begin{tabular}{lllll}
\hline Pain severity & 2 weeks & $\begin{array}{l}3 \text { to } 9 \\
\text { months }\end{array}$ & $\begin{array}{l}\text { 15 to 18 } \\
\text { months }\end{array}$ & $\begin{array}{l}2 \text { to } 3 \\
\text { years }\end{array}$ \\
\hline Overestimate & 8 & 16 & 9 & 13 \\
Underestimate & 7 & 2 & 1 & 4 \\
No difference & 7 & 12 & 4 & 3 \\
\hline
\end{tabular}

after 2 weeks and those after 2 years or more was statistically significant $(t=2 \cdot 61, \quad \mathrm{P}<0 \cdot 02)$. The correlation coefficient between the pain scores fell with increasing duration of treatment.

The errors shown in Table 1 are expressed without regard to the direction of the difference. It is clear from Table 2 that patients usually overestimated their pain severity when previous scores were not available. The differences between scores made after 2 weeks and those made later were statistically significant $\left(\chi^{2}=6 \cdot 09, P<0 \cdot 02\right)$.

\section{Discussion}

The results of this study suggest that patients should be shown their previous scores when making an assessment of pain severity. The work of Jacobsen (1965), though quoted in support of the contrary view, is not inconsistent with our findings. Jacobsen showed that the variation in results was much less in a group of patients who had seen their previous scales. If his patients did not improve, it could be argued that the lack of variation indicated greater accuracy. We would not deny that a patient's assessment is influenced by seeing his previous scores but suggest that this leads to greater precision. Misleading assessments are particularly likely after prolonged treatment when the patient's memory of his initial state has faded. Though we measured pain, the same results would presumably be obtained with serial measurement of other subjective states. This presumably does not apply to objective measuresuch as blood pressure made by an observer who might be biased by previous results.

The availability of a previous score may also be attractive to the patient, who usually expresses himself not in absolute terms but in relation to his previous state. He reports that his pain is the same, better, or worse than on a previous occasion when asked to assess the affects of treatment.

\section{References}

Hart, F. D., and Huskisson, E. C. (1972). Measurement in rheumatoid arthritis. Lancet, 1, 28-30.

Jacobsen, M. (1965). The use of rating scales in clinical research. British Journal of Psychiatry, 111, 545-546. 